\title{
Obstructive Sleep Apnea in Patient with Myasthenia Gravis - A Case Report
}

\author{
Dr. Natraj $\mathrm{M}^{1 *}$, Dr. Gulnar Begum ${ }^{1}$, Dr. S. P Burma ${ }^{1}$
}

${ }^{1}$ Department of Chest \& TB, Andaman and Nicobar Islands Institute of Medical Sciences, Port Blair, Andaman and Nicobar Islands

DOI: $10.36347 /$ sjmcr.2021.v09i04.008

| Received: 05.03.2021 | Accepted: 23.03.2021 | Published: 13.04.2021

*Corresponding author: Dr. Natraj M

\section{Abstract}

About $30 \%$ of the patients with Myasthenia Gravis (MG) develop respiratory muscle weakness. Exacerbation of myasthenia gravis can cause severe respiratory muscle weakness leading to respiratory failure requiring mechanical ventilation. Sleep disorder breathing is seen in about 40 to $60 \%$ of patients with myasthenia gravis. Continuous positive airway pressure (CPAP) will not only reverse sleep disordered breathing but also weakness and fatigability during daytime called as "proximal weakness". Here we report a case of 51 years old male myasthenia gravis patient diagnosed with obstructive sleep apnea (OSA). After initiation of CPAP therapy patients OSA symptoms improved along with his paradoxical weakness.

Keywords: Myasthenia gravis, Obstructive sleep apnea, Paradoxical weakness, CPAP.

Copyright $\odot 2021$ The Author(s): This is an open-access article distributed under the terms of the Creative Commons Attribution 4.0 International License (CC BY-NC 4.0) which permits unrestricted use, distribution, and reproduction in any medium for non-commercial use provided the original author and source are credited.

\section{INTRODUCTION}

Myasthenia gravis (MG) is a rare autoimmune neuromuscular disorder affecting the junction of the skeletal muscle. This results in respiratory muscle weakness in about $30 \%$ of the patients [1]. It is characterized by immunological attack on acetylcholine receptors and subsequent defect of neuromuscular junction transmission (NMJT) within motor end plate [2]. Sleep disordered breathing (SDB) is seen in patients with myasthenia gravis with 40 to $60 \%$ of the patients having obstructive sleep apnea (OSA) [3]. Continuous positive airway pressure (CPAP) usage reverses OSA symptoms and also paradoxical weakness. Risk factors for OSA in MG patients include age, male sex, obesity and steroid usage [4].

\section{CaSe RePORT}

A 51 years old male myasthenia gravis patient presented to the department of chest \& TB with complaints of excessive day time sleepiness, irritability, inability to concentrate, history of falling asleep while watching TV and while riding vehicle. Patient also gave history of weakness and fatigability in the mornings. Patients STOPBANG were 6/8 (Yes for snoring, tiredness, observed apnea, high blood pressure, age more than 50, male gender). Patient was then subjected to overnight polysomnography. Patient apnea hypopnea index was indicative severe OSA. CPAP titration study was done and patient was discharged with CPAP pressure of $8 \mathrm{cms}$ of $\mathrm{H} 2 \mathrm{O}$. Within a month of initiation of CPAP therapy patients symptoms drastically reduced along with his paradoxical weakness.

\section{DisCUSSION}

Onset of MG can be sudden or insidious with the course of the disease varying from patient to patient. Clinical presentation is characterized by muscle weakness and fatigue including the respiratory muscles. It is estimated that $30 \%$ of the patients with $\mathrm{MG}$ develop respiratory muscle weakness [5]. Prevalence of asymptomatic and symptomatic OSA in general population is $5 \%$ and $20 \%$ respectively. But the prevalence of OSA in patients with neuromuscular disorders is largely unknown [6]. One study estimates the prevalence to be $36 \%$ [7]. Studies have shown that after using CPAP in patients with MG along with their OSA symptoms even muscle weakness improves [8]. Sleep disturbances factors such as sleep fragmentation, sleep deprivation, and partial arousal can itself contribute to muscle weakness [9]. Respiratory insufficiency related to unrecognized OSA can lead to unwanted and increase usage of steroid causing central obesity and weight gain which can in turn worsen the OSA [1]. Hence OSA screening must be done in all patients with MG not only to improve patient's quality 
of life but also to avoid unwanted increase in corticosteroid dosage.

\section{REFERNCES}

1. Quera- Salva MA, Guilleminault C, Chevret S, Troche G, Fromageot C, McCann CC, Stoos R, De Lattre J, Raphael JC, Gajdos P. Breathing disorders during sleep in myasthenia gravis. Annals of Neurology: Official Journal of the American Neurological Association and the Child Neurology Society. 1992 Jan;31(1):86-92.

2. YC Lai, JY Chen, HD Wu. Sleep Disordered Breathing in Myasthenia Gravis. Journal of Clinical Sleep Medicine, 2016;12(5).

3. Wood SJ, Slater CR. Safety factor at the neuromuscular junction. Prog Neurobiol. 2001;64:393-429.

4. Yeh JH, Lin CM, Chiu HC, Bai CH Home sleep study for patients with myasthenia gravis. Acta Neurol Scand. 2015;132:191-5.
5. Ji KH, Bae JS. CPAP therapy reverses weakness of myasthenia gravis: role of obstructive sleep apnea in paradoxical weakness of myasthenia gravis. J Clin Sleep Med. 2014;10:441-2.

6. Zulueta JJ, Fanburg BL. Respiratory dysfunction in myasthenia gravis. Clin Chest Med, 1994, 15: 683-691

7. Young T, Peppard PE, Gottlieb DJ. Epidemiology of obstructive sleep apnea: a population health perspective. Am J Respir Crit Care Med. 2002;165:1217-39.

8. Nicolle MW, Rask S, Koopman WJ, George CF, Adams J, Wiebe S. Sleep apnea in patients with myasthenia gravis. Neurology. 2006;67:140-2.

9. Romero-Corral A, Caples SM, Lopez-Jimenez F, Somers VK. Interactions between obesity and obstructive sleep apnea: implications for treatment. Chest. 2010;137:711-9. 